Artigo Original

\title{
Experiências e percepçóes relacionadas ao gênero nas práticas profissionais de homens terapeutas ocupacionais
}

\author{
Experiences and perceptions related to gender in the professional \\ practices of male occupational therapists
}

\author{
Gabriel Paiva Ferreira ${ }^{a}$ (D), Marta Carvalho de Almeida ${ }^{a}$ (D) \\ ${ }^{a}$ Faculdade de Medicina, Universidade de São Paulo - USP, São Paulo, SP, Brasil.
}

Como citar: Ferreira, G. P., \& Almeida, M. C. (2022). Experiências e percepçóes relacionadas ao gênero nas práticas profissionais de homens terapeutas ocupacionais. Cadernos Brasileiros de Terapia Ocupacional, 30, e2984. https://doi.org/10.1590/2526-8910.ctoAO22622984

\begin{abstract}
$\underline{\text { Resumo }}$
Introduçáo: Estudos feministas contribuíram para o entendimento dos papéis de gênero atribuídos à mulher e ao homem enquanto processos socialmente construídos e não biologicamente determinados. No trabalho em saúde no Brasil, marcado pela predominância numérica de mulheres, a divisão sexual do trabalho é influenciada pela naturalização do cuidado como atributo feminino. $\mathrm{Na}$ terapia ocupacional, segundo o Conselho Regional da categoria, apenas 3,7\% dos profissionais do Estado de São Paulo são homens, o que confere singularidade às relaçôes entre gêneros na profissão. Objetivo: Busca-se identificar e analisar experiências e percepçôes relacionadas ao gênero entre terapeutas ocupacionais autodeclarados homens. Método: Estudo qualitativo de tipo exploratório, realizado por meio de entrevistas em profundidade com cinco terapeutas ocupacionais no município de São Paulo, SP, Brasil, posteriormente analisadas por meio de análise temática. Resultados: Os entrevistados identificaram experiências que consideram ser privilégios de gênero não dissimulados, principalmente no que tange ao acesso ao emprego e à valorização profissional. Percebem que, no ambiente profissional, atuam estereótipos ligados ao padrão de comportamento atribuído ao gênero masculino, associando-o à força, autoridade e poder. Em se tratando de relaçốes de cuidado com usuários, alguns participantes não percebem a presença de normas de gênero, o que parece convergente com a invisibilidade social desses processos. Conclusáo: Questóes de gênero estão presentes nas vivências profissionais dos entrevistados, os quais, de modo geral, percebem-nas sob uma perspectiva crítica. Mostra-se relevante para a terapia ocupacional brasileira que novos estudos adensem reflexóes e abordem distintas faces das relaçôes de gênero na prática profissional.
\end{abstract}

Palavras-chave: Terapia Ocupacional, Ocupaçóes em Saúde, Divisão de Trabalho Baseada no Gênero. 


\section{$\underline{\text { Abstract }}$}

Introduction: Feminist studies have contributed to the understanding of the gender roles assigned to women and men as socially constructed and not biologically determined processes. In health work in Brazil, marked by the numerical predominance of women, the sexual division of labor is influenced by the naturalization of care as a female attribute. In occupational therapy, according to the Regional Council of the category, only 3.7\% of professionals in the State of São Paulo are male, which gives uniqueness to gender relations in the profession. Objective: We seek to identify and analyze gender-related experiences and perceptions among self-declared male occupational therapists. Method: Qualitative exploratory study, carried out through in-depth interviews with five occupational therapists in the city of São Paulo, SP, Brazil, later analyzed through thematic analysis. Results: Respondents identified experiences that they consider to be undisguised gender privileges, especially with regard to access to employment and professional development. They perceive that, in the professional environment, there are stereotypes linked to the pattern of behavior attributed to the male gender, associating it with strength, authority and power. When it comes to care relationships with users, some participants do not perceive the presence of gender norms, which seems to converge with the social invisibility of these processes. Conclusion: Gender issues are present in the professional experiences of the respondents, who, in general, perceive them from a critical perspective. It is relevant for Brazilian occupational therapy that new studies increase reflections and address different aspects of gender relations in professional practice.

Keywords: Occupational Therapy, Health Occupations, Gender-Based Division of Labor.

\section{Introdução}

\section{Questóes de gênero no trabalho em terapia ocupacional}

Este é um estudo interessado em refletir sobre as condiçóes experimentadas e percebidas atualmente por terapeutas ocupacionais que se autodeclararam homens, considerando suas relações de trabalho no campo da terapia ocupacional em saúde.

De acordo com o Conselho Regional de Fisioterapia e Terapia Ocupacional que abrange o Estado de São Paulo, apenas 219 (3,7\%) informaram serem do sexo masculino, entre os 5.906 terapeutas ocupacionais inscritos (Conselho Regional de Fisioterapia e Terapia Ocupacional, 2021). A expressiva predominância de mulheres na terapia ocupacional, contudo, é parte de um cenário mais amplo e não recente. Segundo Silva (2020), baseada em dados do Instituto Brasileiro de Geografia e Estatística, em 2013 as carreiras profissionais do setor de ciências biológicas, saúde e afins já contavam com $65,2 \%$ de força de trabalho feminina. Nesse mesmo ano, as mulheres representavam 73,4\% das matrículas nos cursos de nível superior da área da saúde, com destaque para a Enfermagem e as profissóes relacionadas à Reabilitação (Silva, 2020), indicando uma das faces do que alguns estudos denominaram de feminização das profissōes de saúde no Brasil (Matos et al., 2013). 
Cabe lembrar que a presença feminina no mercado de trabalho em geral, bem como no mundo do trabalho em saúde, tem sido analisada com diferentes interesses. Dentre esses situam-se aqueles que buscam compreender os processos sociais que condicionam essa realidade, bem como outros que enfatizam as relaçóes históricas que conectaram o universo feminino ao dos cuidados dedicados a outros seres humanos.

$\mathrm{Na}$ terapia ocupacional, Vogel et al. (2002) discutiram esse tema sob o prisma da associação entre estereótipos do feminino, referenciais de classe social e a origem da profissão, levando em conta suas raízes nos Estados Unidos, quando Eleanor Clarke Slagle, assistente social e umas das fundadoras da terapia ocupacional nesse país, estabeleceu a infinita bondade, paciência e gentileza - além de expressão física adequada e voz agradável - como pré-requisitos para se tornar profissional da área. Lembraram ainda que, ao se ter indicado o "espírito maternal" como parte dos requisitos para estudantes de terapia ocupacional nos primeiros cursos criados, a profissão foi praticamente vetada aos homens (Vogel et al., 2002).

Figueiredo et al. (2018), baseadas na literatura que aborda a história da terapia ocupacional e o trabalho feminino, reiteraram a importância da relação entre o contexto de expansão da presença das mulheres em espaços extradomiciliares nas primeiras décadas do Século XX e a origem da terapia ocupacional. Segundo as autoras, o modelo de segregação de gênero teve influência na criação e desenvolvimento da profissão e em sua ligação com o estereótipo feminino que atribui às mulheres a função natural do cuidado, tendo em conta que a profissão correspondia à normatividade social que orientava o comportamento de certo segmento de mulheres. Assim, dizem, se por um lado as mulheres de classes sociais privilegiadas começavam a exercer atividades extradomiciliares, ingressando no mercado de trabalho e em níveis mais elevados de ensino, por outro ficavam restritas a profissóes consideradas ajustadas aos papéis sociais esperados da mulher, como a terapia ocupacional. Nesse sentido, a ligação da terapia ocupacional com o universo das atividades realizadas na esfera privada e no âmbito da vida cotidiana era um fator relevante para fazer a opção por essa profissão naquele momento (Lopes, 1999; Figueiredo et al., 2018). Monzeli et al. (2019), ao estudarem a criação de programas de formação profissional a partir da década de 1950 em países da América Latina também refletem nessa direção, e consideram que a origem desses programas articulou processos de subordinação do gênero feminino que envolveram o ensino em nível universitário e a entrada no mercado de trabalho em posiçóes de menor prestígio nas hierarquias médicas.

Abordando questóes de gênero sob outro ângulo, alguns estudos têm mostrado aspectos importantes sobre a realidade dos profissionais homens na terapia ocupacional. No Canadá, país em que a proporção de aproximadamente $8 \%$ de profissionais homens tem sido objeto de preocupaçáo entre a categoria profissional por ser considerada pequena, estudo que aplicou questionário junto a 37 profissionais de Ontário (Birioukova et al., 2012) identificou que a maioria vivenciou problemas ligados a normativas estereotipadas de gênero, como ser solicitada a realizar transferências de usuários mais pesados, a conter usuários em episódios agressivos e a consertar equipamentos dos serviços. Entre os participantes do estudo, 26\% esperam deixar a profissão em até 10 anos. Mais recentemente, Beagan \& Fredericks (2018) colocaram em questão até que ponto o equilíbrio numérico entre os gêneros deve continuar a ser tratado como um problema de equidade na terapia ocupacional do Canadá, onde o 
aumento do recrutamento e retenção de homens tem sido um esforço colocado em prática sob o argumento de haver benefícios na diversidade da força de trabalho. $\mathrm{Na}$ discussão proposta, sublinharam dados de estudos que mostraram os homens mais presentes em cargos de gestão, concentrados em algumas áreas de atuação profissional e parte deles tratando a terapia ocupacional como um “degrau” na carreira. Já Maxim \& Rice (2018), em estudo usando questionários online com mulheres e homens terapeutas ocupacionais de Ohio, nos Estados Unidos, concluem que, apesar de haver diferenças de percepçóes sobre a profissão dependentes do gênero, profissionais homens e mulheres estão satisfeitos e seguros, e se sentem contribuindo com a sociedade.

Levando em conta a presença de questóes ligadas ao gênero na terapia ocupacional, nosso estudo se propôs a explorar e discutir as percepçóes de terapeutas ocupacionais homens sobre esse tema. Partindo da intenção de compreendê-las não como retratos do "lugar dos homens" na profissão, mas sim como uma das expressóes da dinâmica de relaçóes de gênero estabelecida no campo profissional, tomamos os estudos feministas como referências fundamentais.

\section{Estudos feministas, questóes de gênero e masculinidade}

Seja enquanto modo de pensamento, seja como conjunto de práticas políticas e sociais, desde o final do Século XIX o feminismo vem dando visibilidade não apenas às mulheres e às questóes femininas, mas às formas perversas da exclusão que se expressam, sobretudo, na esfera pública das sociedades ocidentais (Rago, 1996; Pinto, 2010; Biroli, 2016). Produções teóricas feministas, constituídas por vertentes diversas, deram corpo à desconstrução de concepçóes essencialistas da sexualidade, a leituras feministas da história e a novas conceituações e problematizações na apreensão de diferenças e singularidades, entre outras interpretaçóes originais sobre as desigualdades sociais e as hierarquias edificadas socialmente entre homens e mulheres.

Entre as várias questôes situadas no campo da crítica feminista, o debate sobre gênero, em especial, confrontou ordens epistemológicas e consolidou diálogos entre o feminismo enquanto movimento social e a academia, produzindo impactos importantes na produção científica (Matos, 2008). Notadamente a partir de meados da década de 1970, estudos de gênero, ou ainda, de relaçóes sociais entre os gêneros, atravessaram o discurso sociológico com novas reflexóes, trazendo resultados que envolveram a denúncia da dominação sexista, ideológica e cultural (Scott, 1995; Rago, 1996; Pinto, 2010).

Várias dessas produções operaram com base no pensamento de Joan Scott, que avançou na crítica e na aplicação do termo "gênero", cunhado pelas feministas americanas na década de 1970 para enfatizar o caráter social das distinções baseadas no sexo (Scott, 1995). Em 1985 a autora o definiu como "[...] elemento constitutivo de relaçóes sociais baseadas nas diferenças percebidas entre os sexos" e como "[...] forma primária de dar significado às relaçóes de poder" (Scott, 1995, p. 86).

Esse foi o momento em que se marcou o início da segunda onda do feminismo que, diferentemente da primeira (no Século XIX e início do XX), valorizou a afirmação política das diferenças e das questóes ligadas à diversidade. O que aconteceu a partir daí, para Matos (2008), foi a generalizaçáo da utilização do conceito de gênero como instrumento analítico e empírico de tal forma que, além de sua expansão para várias 
outras disciplinas, assistiu-se, também, à conformação de muitos desses estudos a um "feminismo difuso" ou mesmo à desvinculação desses estudos do pensamento feminista.

Embora o conceito de gênero como instrumento de elaboração teórico-analítica tenha servido essencialmente à explicitação dos processos de subordinação da mulher ao homem, ele também abriu espaço para questionamentos sobre as categorias homem e masculino (Matos, 2008). Conforme afirmou Gardiner (2002) tratando dessa relação, a misoginia criou o feminismo e, por sua vez, o feminismo criou as possibilidades de compreender que os homens também foram encarnados como um gênero específico, definido de acordo com ideais culturais para pessoas com órgãos semelhantes.

Assim, foi na convergência entre os estudos feministas sobre o patriarcado e o interesse no processo de construção das masculinidades e das feminilidades na vida real que o conceito de masculinidade hegemônica foi formulado, na década de 1980, por um grupo de pesquisadores australianos do qual foi expoente Raewyn Connell.

$\mathrm{O}$ conceito, que influenciou fortemente a criação e desenvolvimento de um campo de estudos da masculinidade, definiu-se como uma perspectiva crítica à teoria dos papéis, à noção de "papel sexual masculino" e às noçôes universalizantes sobre a categoria homem. Além disso, conforme assinalam Connell \& Messerschmidt (2013), outras fontes, como o movimento de liberação gay, foram importantes. Ao tratar de modo central os conceitos de diferença e poder, esse movimento desenvolveu uma análise sofisticada da opressão do homem e da opressão pelo homem, dando visibilidade a uma hierarquia das masculinidades por meio de experiências de homens homossexuais com a violência e o preconceito dos heterossexuais. Nesse sentido, a masculinidade hegemônica foi tratada como um padrão de práticas (e não apenas de expectativas) que impóe a forma supostamente mais apropriada de ser um homem, exigindo que todos os homens se posicionem em relação a essa. É uma configuração prática que orienta a posição dos homens na estrutura das relações de gênero e, enquanto tal, é entendida como um elemento fundamental na produção da continuidade da dominação dos homens sobre as mulheres (Connell \& Messerschmidt, 2013). Enraizada na esfera da produção, nas arenas políticas e em diversas práticas sociais, a masculinidade hegemônica tem como fundamento a valorização da competição, da busca pelo poder e sucesso, das expressóes de força, virilidade, confiança e de domínio e controle, conforme também discutiu Bento (2015).

Levando em conta as críticas dirigidas ao conceito de masculinidade hegemônica que se deram com a expansão de sua aplicação nas décadas posteriores, Connell \& Messerschmidt (2013) consideram importante a incorporação de novas perspectivas associadas ao conceito, mas destacam a importância de se manter a recusa em defini-lo enquanto um traço fixo ou tóxico de caráter, como se vê em algumas de suas apropriaçóes mais recentes. De fato, desde meados da década de 1950 Connell (1995) já chamava a atenção, também, para a existência de uma narrativa convencional sobre a construção da masculinidade, que afirma que todos os meninos são levados a adotar conduta e sentimentos que são construídos a partir da pressão - de famílias, escolas, mídia, organizaçóes e sistema político, entre outros grupos sociais - para que se distanciem do comportamento feminino e reprimam sentimentos. Embora concorde com a base dessas afirmaçóes, o autor enfatizou sua incompletude, destacando aspectos como a dimensão ativa dos sujeitos ao se apropriar dessa masculinidade, bem como o fato de que outras masculinidades também são produzidas concomitantemente na 
sociedade. Convém então, segundo ele, considerarmos sempre que existem "masculinidades" em contínua disputa no jogo social (Connell, 1995). Nele, algumas masculinidades são subordinadas a outras.

No Brasil, a influência de estudos de gênero e da dinâmica da relação masculinofeminino no debate sobre as masculinidades também pode ser notada e ganhou maior visibilidade em 1998, em coletânea de textos organizada por Margareth Arilha (Arilha et al., 1998). A publicação reuniu uma vertente importante da produção brasileira.

Já Nolasco (1993), partindo de sua experiência com grupos de homens em consultório de atenção psicológica e tendo seguido em direção distinta a desses estudos, ressaltou a intensidade das tensóes vividas pelos homens na tentativa de se alinharem a um desempenho social que não comporta seus próprios desejos e limites. $\mathrm{O}$ autor deu ênfase ao argumento de que o cotidiano dos homens é caracterizado pela participação em um sistema de valores no qual determinados comportamentos são interditos por um constructo que o reduz a "ser macho" (Nolasco, 1993). Realçando a socialização dos meninos como processo no qual a negação e desvalorização das demandas afetivas abre espaço para a ilusão de que encarnar o estereótipo do macho responderá suas necessidades, creditou a esse modelo a tutela e o controle dos desejos dos homens. $\mathrm{O}$ modelo, por sua vez, seria retroalimentado pela simplificação da subjetividade masculina aprisionada.

Essa abordagem, entre outras, foi criticada por Oliveira $(1998,2004)$ em mais de uma obra, nas quais a tomou enquanto componente de um discurso que coloca o homem na condição de vítima de um conjunto de fatores sociais e psíquicos, no contexto da articulação entre as dinâmicas típicas do capitalismo e a construção da masculinidade. Nesse discurso, mesmo as expressóes de força por meio da violência são tomadas como máscaras para a fragilidade e insegurança masculina, em operação de inversão que transforma o réu em vítima. Dessa forma colocado, o problema se desloca: o culpado não é o macho, mas o papel de macho, afirma Oliveira (2004).

Também é dessa perspectiva que Oliveira (2004) critica determinadas abordagens sobre a chamada "crise de masculinidade", que enquanto reflexo do movimento feminista da década de 1960 teria levado a um mal-estar entre os homens e ao empreendimento de uma busca por um novo modelo de expressão de subjetividades. Sendo formulaçóes que o autor denomina de vitimárias, cumprem a função de tornar opaca a percepção de que, antes de serem vítimas, os homens são beneficiários do sistema de gênero. $\mathrm{O}$ resultado dessa abordagem, então, seria um apelo para a flexibilização de papéis e a atenção às necessidades dos homens, e não para a distribuição igualitária de poder entre homens e mulheres.

Ainda que com outra preocupação central, Silva (2006) também aborda a crise de masculinidade. $\mathrm{O}$ autor ressalta a insuficiência dos novos modelos de masculinidade que se desdobraram desse debate, alertando que seria limitado se ater à criaçáo de padróes de oposição aos modelos tradicionais de masculinidade que definem o homem em uma estrutura polarizada negativa (não pode chorar, não pode demonstrar sentimentos, não pode ser um fraco ou perdedor) e afirmativa (ser pai, líder, corajoso, viril, independente), por meio da noção de "ter" (ter músculos, dinheiro, emprego fixo e tantas mulheres quanto possível) e da noção de "poder" ligada ao comportamento, como "fazer um 
filho", "manter relações sexuais com várias mulheres", "sustentar a família”, entre outros (Nolasco, 1993).

Por fim, cabe resgatar as considerações de Hirata \& Kergoat (2007) ao atribuírem ao feminismo as bases teóricas que renovariam a compreensão da divisão sexual do trabalho. As autoras lembram que foi a partir da tomada de consciência de uma opressão específica ligada ao trabalho - aquele realizado gratuita e invisivelmente pelas mulheres em nome da natureza, do amor e do dever maternal - que o movimento teve início. Nesse sentido, os trabalhos de antropólogas feministas na década de 1970 foram fundamentais para compreender que a divisão sexual do trabalho não traduzia apenas uma complementaridade de tarefas, mas uma relação de poder dos homens sobre as mulheres. Hirata \& Kergoat (2007) deixam claro: as condiçóes em que vivem homens e mulheres não são um destino biológico, mas construções sociais. E o trabalho representa uma base material em que as relaçóes sociais de sexo se expressam e configuram a divisão sexual do trabalho, em formas adaptadas historicamente em cada sociedade. Embora essa divisão tenha por característica central a destinação prioritária dos homens à esfera produtiva - com apreensão de funçóes de forte valor social agregado - e das mulheres à esfera reprodutiva, ela não é rígida nem imutável, compreendendo diferentes dinâmicas e contínuas reconfiguraçôes que devem ser investigadas.

$\mathrm{O}$ estudo desenvolvido procurou responder, em primeira instância, se questóes relacionadas ao gênero têm sido percebidas por terapeutas ocupacionais homens como parte de suas práticas profissionais, envolvendo suas relaçóes interpessoais com usuários e colegas de trabalho. A partir dessa orientação, buscamos identificar e compreender como percebem e dão significados à sua realidade profissional enquanto sujeitos de gênero.

\section{Percurso Metodológico}

Foi realizado estudo qualitativo de tipo exploratório com terapeutas ocupacionais homens que atuam no campo da saúde, no município de São Paulo. Ancorado nos fundamentos da pesquisa social, o método inclui concepçóes teóricas eleitas para a construção do objeto (Minayo et al., 2016) e foi desenvolvido com o uso de entrevistas em profundidade com profissionais que corresponderam ao requisito de estarem graduados há, no mínimo, três anos. Esse critério de inclusão foi definido a fim de possibilitar que, provavelmente, os participantes tivessem acumulado vivências significativas na profissão.

O primeiro participante foi recrutado por meio de sua manifestação voluntária, que aconteceu atendendo à divulgação e chamamento para o estudo em uma rede social virtual. Dado o baixo número de homens atuando na terapia ocupacional no Brasil, os demais colaboradores foram definidos por meio do uso da técnica bola de neve, que consiste em uma abordagem em cadeia para a seleção de participantes (Aktinson \& Flint, 2001): o primeiro entrevistado indicou o segundo e assim sucessivamente, até que se atingiu o número esperado. Os participantes aceitaram voluntariamente o convite para que falassem ao pesquisador na condição de homens terapeutas ocupacionais, o que nos permitiu inferir que se percebem pertencentes a essa categoria.

Buscando criar um processo que privilegiasse o diálogo em sua expressão mais espontânea possível, produziu-se um tipo de interação na qual as percepçóes e experiências profissionais mais significativas pudessem ser os elementos centrais das narrativas. Para isso, a pergunta norteadora das entrevistas foi: como tem sido sua 
experiência profissional enquanto homem na terapia ocupacional, que é majoritariamente composta por mulheres?

Colaboraram com a pesquisa, entre os meses de junho a novembro de 2019, 5 (cinco) terapeutas ocupacionais que atuam profissionalmente em diferentes unidades do Sistema Único de Saúde (SUS) do município de São Paulo, em contextos nos quais existe trabalho em equipe. Com cada um deles foi realizada uma entrevista presencial, em local público de sua escolha, com tempo médio de duraçáo de 60 minutos.

As entrevistas foram gravadas e transcritas na íntegra logo após a sua realização. Os textos resultantes desse processo foram submetidos à análise temática que, conforme orientou Duarte (2004), deve abranger as etapas de conferência de fidedignidade, edição, fragmentação em unidades de significação e, por fim, de interpretação de cada uma dessas unidades, de forma a gerar um reagrupamento em categorias de análise (ou eixos temáticos, como menciona a autora). No estudo desenvolvido, as categorias de análise não foram definidas previamente, tendo emergido no momento da análise em diálogo com os objetivos propostos.

Por fim, o material empírico foi interpretado à luz da literatura de referência, que sustenta a análise sobre relaçôes de gênero e suas ressonâncias no mundo do trabalho.

O projeto da pesquisa foi apreciado e aprovado pelo Comitê de Ética em Pesquisa da Faculdade de Medicina da Universidade de São Paulo, tendo recebido o parecer $n^{\circ}$ 3.731.614 em junho de 2019. Os direitos dos participantes foram protegidos por meio da disponibilizaçáo de todas as informaçóes relevantes sobre o estudo, incluindo seus riscos e benefícios, bem como pelo atendimento das normativas que regulamentam as pesquisas com seres humanos. $\mathrm{O}$ anonimato foi preservado pelo uso de nomes fictícios nas divulgaçóes de resultados do estudo.

\section{Resultados e Discussáo}

A maior parte dos participantes atuava, no momento da pesquisa, no campo da saúde mental, e já havia tido experiência profissional em mais de uma unidade assistencial, conforme mostra a Tabela 1 .

Tabela 1. Dados gerais dos entrevistados.

\begin{tabular}{cccc}
\hline Participante & Idade & Tempo de formado & $\begin{array}{c}\text { Experiência profissional por tipo de } \\
\text { unidade prestadora de serviço }\end{array}$ \\
\hline Caio & 33 & 10 anos & CAPS IJ, SRT* e IES* \\
\hline Daniel & 29 & 6,5 anos & Amb. de reab. física em hospital terciário* \\
\hline Lucas & 28 & 3,5 anos & CR, CAPS AD* e CAPS Adulto \\
\hline Mateus & 26 & 3,5 anos & CAPS AD* \\
\hline Roberto & 31 & 7 anos & UBS, Hospital secundário* e \\
\hline
\end{tabular}

*Locais atuais de trabalho. Fonte: elaboração própria. 
Os participantes relataram trabalhar ou terem trabalhado nas seguintes unidades: Centro de Atenção Psicossocial (CAPS) - no atendimento a usuários de álcool e outras drogas (CAPS AD), no atendimento a adultos (CAPS adulto) e na atenção à infância e juventude (CAPS IJ) -, Centro de Reabilitação (CR), Unidade Básicas de Saúde (UBS), Hospital de nível secundário, Ambulatório de reabilitação física em hospital de nível terciário, Serviço Residencial Terapêutico (SRT) e Serviço de Atenção Especializada em Doenças Sexualmente Transmissíveis e Síndrome da Imunodeficiência Adquirida (SAE - DST/AIDS). Além do exercício na assistência, um dos entrevistados também atuava como docente em um curso de graduação em terapia ocupacional.

O tempo de inserçáo no mercado de trabalho variou no grupo de entrevistados entre 3 anos e meio e 10 anos. Quatro dos cinco colaboradores foram graduados em instituiçóes públicas de ensino e todos são relativamente jovens, com idade média de 29,4 anos.

\section{Relaçóes de gênero nas práticas de terapia ocupacional: desigualdades não dissimuladas entre profissionais}

Todos os participantes consideraram vivenciar em diversas ocasióes, e sob diferentes formas, o que consideram ser privilégios de gênero no exercício da profissão. Em relação ao ingresso no mercado de trabalho, a preferência vem sendo explícita nos processos seletivos, relata Lucas.

Eu tô lembrando agora, também, que teve duas situaçóes que eu fui chamado para trabalho [...] E eu náo fui para nenhum desses dois. Mas teve o discurso: vai ser ótimo ter um homem na equipe! Então, sem eu fazer nada, [por] puro privilégio, por eu ser homem, ia ser bom estar ali.

Roberto também teve a mesma percepção em situações nas quais buscava por uma vaga de emprego. "Nossa! TO homem!", disse ter ouvido. "As pessoas querem; quase te oferecem [o emprego]. Te dão outras coisas, outros privilégios...", afirmou. O termo "as pessoas" se refere a gestores ou outros trabalhadores responsáveis por selecionar candidatos ao cargo.

$\mathrm{O}$ acesso desigual a atividades de maior prestígio também foi identificado pelos entrevistados como exemplo das vantagens masculinas na terapia ocupacional e na área de saúde, de modo geral. No que diz respeito à ocupação de cargos ou postos mais valorizados socialmente, Caio comenta que tem percebido muitos homens "[...] nos lugares que são lugares de poder, na coordenação, direção...”. E que também tem observado vários terapeutas ocupacionais homens realizando atividades profissionais no ensino superior, o que lhe parece ser uma expressão das desigualdades de gênero, já que a presença no meio acadêmico seria superior à proporcionalidade entre homens e mulheres em exercício na profissão.

Essas percepçôes parecem expressar o que Hirata \& Kergoat (2007) indicaram ser os princípios organizadores da divisão sexual do trabalho decorrente das relaçóes sociais entre os sexos: o princípio da separação e o princípio hierárquico. O primeiro se refere ao fato de existirem alguns trabalhos considerados adequados para homens e outros para mulheres. O segundo diz respeito ao fato de que o trabalho dos homens é interpretado 
socialmente como de maior "valor". Desse modo, vemos que, apesar do "cuidado" ter sido naturalizado como um trabalho feminino - assim categorizado pelo princípio da separação -, a atuação de homens em campos profissionais que o abrange, como a terapia ocupacional, dá a eles maior prestígio e reconhecimento por parte da equipe quando comparados às colegas mulheres, fenômeno regido pelo princípio hierárquico. Roberto afirma: "[...] eu era mais ouvido em comparação com TOs [terapeutas ocupacionais] mulheres ou [...] com outras profissionais que fossem mulheres. Eu sempre senti que, na verdade, te dão mais ouvido. "

Ainda confirmando as desigualdades, alguns entrevistados notam que existem características positivas indevidamente atribuídas a eles, em clara demonstração de uma supervalorização da sua capacidade profissional, de suas opinióes e, também, de sua autoridade. "Eu tinha uma colega mulher e eu sentia que muitas coisas voltaram mais para mim. E[...] não tinha nenhum motivo a não ser pelo fato de eu ser homem”, afirma Roberto.

Roberto detalha situaçôes nas quais notou ter sido percebido com qualidades superiores em relação às mulheres, pelo único fato de ser homem:

[... Eu trabalho com uma mulher, ela de manhã e eu à tarde. Ai muitas vezes me procuram para algumas coisas e eu fico mais como referência [profissional] do que ela, sendo que para mim ela sabe muito mais coisas do que eu [sobre aquele tema].

Reflete, ainda, sobre as consequências que decorrem de se atribuir mais valor às suas opinióes profissionais apenas por ser homem, e náo por outros fatores relacionados às suas qualificações. Afirma que se sente mais ouvido por colegas "[...] comparado com terapeutas ocupacionais mulheres ou [...] com outras profissionais mulheres", o que acaba por lhe trazer um reconhecimento profissional ao qual não se dedicou a obter: "[...] fui virando uma referência meio sem querer".

As percepçôes dos entrevistados também nos conduziram às relaçôes entre o mundo do trabalho e outros marcadores, além do gênero - como a orientação sexual e a raça em apoio ao que afirma Biroli (2016): a hierarquização das relaçóes entre homens e mulheres está fundamentada não apenas no gênero, mas também nas variáveis raça e classe, através de uma relação de interdependência que configura a dinâmica da desigualdade. Para a autora, é necessário compreender e enfrentar os padróes de gênero produzidos no trabalho através da intersecção entre essas três variáveis (Biroli, 2016). Alguns entrevistados, declarando-se homossexuais, afirmaram que, mesmo não se expressando de acordo com o padrão de comportamento heteronormativo, são privilegiados em relação às mulheres no trabalho. "[...] Mesmo assim, o fato de você ser homem te coloca em outro lugar", afirma Caio, sugerindo que reconhece a existência de diferentes masculinidades no contexto do trabalho em saúde, a hierarquia que os organiza e a posição privilegiada que os homens ocupam em relação às mulheres.

Para parte dos entrevistados, os privilégios são resultado da estrutura patriarcal da sociedade brasileira, que coloca o masculino em destaque nas relações da esfera pública. E esses são, de várias formas, reproduzidos nos serviços de saúde. Vários deles mencionaram criticamente o machismo como um componente orgânico das relaçôes interprofissionais, considerando sua forte influência no campo das diferenças que recaem entre homens e mulheres na terapia ocupacional. Caio refere, inclusive, que a reflexão sobre esse cenário o tem levado a desenvolver atitudes mais atentas: 
[...] O tempo todo en fico nesse exercicio de ir e vir, porque eu sei que [...] essa figura masculina já me coloca [...] automaticamente alguns passos à frente de uma mulher. [...] Se for uma mulher negra, eu tô milhöes [de passos] lá na frente. [...] Então, eu fico o tempo todo discutindo isso comigo mesmo, sabe? A forma como eu me coloco..., a forma como eu falo..., de que jeitos a gente vai tentando pensar essa questão de igualdade de gênero..., de como dá para colocar ela na prática...

A narrativa dos terapeutas ocupacionais sobre seus privilégios nos leva a observar semelhanças entre percepçóes e características dos nossos entrevistados em relação ao grupo de homens participantes do estudo de Bento (2015), ao qual a autora atribuiu a expressão de uma "masculinidade crítica". Nesse grupo bem delimitado, composto por homens de classe média, relativamente intelectualizados e psicologizados, a autora identificou um segmento que reflete criticamente sobre os modos de socialização primária dos homens e negam, ou até repulsam, aqueles que performatizam o modelo tradicional de masculinidade, reforçando o fenômeno da coexistência social de múltiplas masculinidades.

\section{Os terapeutas ocupacionais homens na relação com usuários dos serviços}

Existem diferenças na atuação profissional entre os terapeutas ocupacionais, segundo alguns entrevistados. Essa afirmação, contudo, foi trazida para enfatizar que as diferenças observadas não poderiam ser explicadas por características supostamente naturais, mas sim por experiências profissionais prévias. Dessa perspectiva, habilidades aprendidas e exercitadas anteriormente, mesmo que em uma área de especialidade diferente daquelas em que se encontram no momento, seriam transpostas e atualizadas como referências importantes para o raciocínio técnico-profissional, levando a diferenças importantes entre os profissionais de terapia ocupacional. Assim, para Roberto, "[...] como ela [terapeuta ocupacional da mesma unidade] tem mais experiência em reabilitação, e eu um pouco mais em saúde mental e atenção primária, isso influencia muito no nosso olhar". No exemplo trazido, Roberto ressalta um critério de identificação bastante reconhecido e adotado na profissão. As denominadas "áreas de atuação" são referentes constituídos não apenas por contornos epistêmicos e metodológicos, mas também por componentes simbólicos que agem na dinâmica de relaçóes entre os profissionais.

Nessa mesma linha de argumentação, esses participantes valorizaram as biografias como agentes da construção de particularidades no relacionamento com os usuários dos serviços, como expressa Caio: "[...] tem uma diferença muito mais pela minha história de vida, pelas experiências que eu fui passando, pelo lugar que eu fui ocupando ao longo do processo". E, dessa perspectiva, também se coloca Daniel, afirmando que "[...] nós [terapeutas ocupacionais] seguimos uma mesma filosofia, [...] mas somos pessoas diferentes".

Embora o sentido buscado pelos entrevistados nessas afirmaçóes pareça ser a reiteraçáo da recusa em associar características e qualificaçóes profissionais a fatores que precedem a vida social, cabe-nos olhar para o que fica de fora dessa interpretação, na medida em que não atenta para a força da construção diária e incessante da identidade de gênero, que se dá de maneira tênue no tempo, compondo as histórias de vida e a realidade cultural comum. Conforme Butler \& Lourties (1998), o fundamento da identidade de gênero é a repetição estilizada de atos performativos que envolvem gestos 
corporais, posturas, falas e encenaçôes que são moldadas em relações de poder que reforçam uma estrutura binária de gênero e adquirem efeitos por meio de sua reificação e naturalização. Desse ponto de vista, a singularidade das biografias é constituída, e não independente, da performance de gênero.

Partindo dessa reflexão, notamos que alguns entrevistados conjugam narrativas contraditórias sobre a performance de gênero, levando-nos a indagar sobre o apoio que a reprodução de papeis tradicionais - como a identificação entre o gênero masculino e as brincadeiras com ênfase motora - recebem de saberes que integram o meio profissional. Por exemplo, Caio refere a importância de sua presença nas atividades lúdicas realizadas com meninos no CAPS IJ e relata que, naquele espaço, eles buscavam atividades consideradas mais masculinas: "[...] as brincadeiras eram um pouco mais grotescas, no sentido de ser luta, assim. E as meninas faziam opção de ficar com as mulheres ali". Observamos, aqui, a narrativa de uma típica situação na qual a presença masculina é associada de modo naturalizado a uma maior diversidade de experiências motoras, cognitivas e psicossociais, e identificada com parte dos argumentos que sustentam a desejada paridade de gêneros na profissão, defendida em países como os EUA e Canadá. De outro modo, tomando a perspectiva feminista, o que nos caberia impulsionar é a reflexão sobre como profissionais da terapia ocupacional poderiam contribuir para evitar a reprodução de padróes universalizantes de gênero que, presentes em diferentes interaçôes desde a infância, não apenas limitam as experiências vitais e naturalizam elementos da ordem da cultura, mas também perpetuam desigualdades de gênero (Scott, 1995).

Nota-se assim que, se por um lado esses participantes afirmaram não manejar a realidade profissional com base em uma perspectiva binária de gênero, por outro também não a identificaram claramente como um espaço de construção contingencial de feminilidades e masculinidades. Em outras palavras, não observaram que o trabalho, não sendo apenas uma esfera da expressão de papéis de gênero, tem sentido criativo, isto é, nele também se constrói a conformidade de gênero.

Em algumas entrevistas encontramos outras narrativas que, igualmente, pareceu-nos serem reflexos da reprodução naturalizada de noçóes e conceitos que informam a profissão no que diz respeito às relaçôes entre profissionais e usuários. Nelas se afirmam a facilidade dos terapeutas ocupacionais homens para a criação de vínculos com usuários do mesmo gênero e, por consequência, para a abertura de um espaço potencial de manejo de questóes diretamente ligadas ao corpo e à saúde, bem como ao imaginário masculino - o que, segundo esses participantes, poderia não se dar na relação dos usuários com uma profissional mulher. Esse significado positivo quanto ao lugar dos homens na profissão aparece na percepção de Roberto, ao relatar uma experiência de atendimento a um usuário encaminhado a ele após não ter havido a devida vinculação profissional com uma colega de equipe. No processo, ele afirma, percebeu que os problemas de interação entre o usuário e a profissional que o precedeu refletiam dificuldades baseadas no gênero: "[...] ele foi criando um vínculo comigo e uma vez ele falou que tinha uma questão com mulher... e que era difícil para ele."

Reforçando o que entende como uma facilidade na relação dos terapeutas ocupacionais com usuários homens, Lucas refletiu sobre a relação entre diferentes masculinidades a partir de suas experiências na condição de um dissidente do modelo hegemônico. Em sua percepção, tratando-se de usuários de CAPS AD, junto aos quais 
coordenou um grupo terapêutico, o fato de ser homossexual, ou ainda, a falta de adoção de padróes de comportamento heteronormativo, não interferiu negativamente na produção do cuidado: "Era um grupo que só ia homens, que eles estavam sempre ali. E eu sinto que eu conseguia cuidar para caramba [...] apesar de eu ser gay, apesar de eu também não responder a todos os estereótipos, isso rola”. Caberia, contudo, que novas reflexóes se desdobrassem para além da percepção de que a masculinidade dissidente não representa um impedimento na prática profissional, tomando por questão as possibilidades de que masculinidades dissidentes gerem diferentes representaçóes das relaçóes de cuidado e estabeleçam novas configuraçóes de vínculos de atenção e cuidado, contribuindo com a quebra de padróes. Em um contexto no qual as tensóes por hegemonia envolvem estratégias complexas e frequentemente invisibilizadas, desvelar distintas e diversas formas de performar o gênero pode compor a análise de resistências e subordinações nos processos de constituição de iniquidades (Grollmus, 2012).

\section{Estereótipos da masculinidade na prática profissional}

No âmbito dos serviços de saúde mental, relatos de certa preferência na contratação de homens para compor equipes e desenvolver atividades que seriam, em teoria, mais adequadas à natureza masculina - como a contençáo física de usuários em crise apontam para a reprodução de estereótipos do "macho" (Nolasco, 1993) e envolvem a suposição da predisposição masculina para a tomada de iniciativas ou de posiçóes ofensivas, firmes e intransigentes. Lucas relata:

Vejo casos em que a gente tinha que fazer contenção, verbal elou física, junto a algum usuário: eu sempre estava em cena, eu sempre era chamado. Acho que por ser maior, por ser mais forte e tal. Mas acho que tem uma coisa simbólica mesmo, que se reproduz, assim.., do homem ser autoridade.

Do mesmo modo, Caio narra: "Já ouvi de colegas que são gestores [...] de que tem uma opção de poder fazer essa mescla na questão de gênero dentro da saúde mental. Então, [homens] têm uma leve vantagem."

As percepçóes dos participantes remetem ao fato de que o comportamento profissional esperado dos homens que se encontram em situaçóes de conflito no trabalho deve impor respeito e autoridade, de modo a se expressar de duas formas principais: através da articulação do discurso verbal e/ou pela presença do corpo masculino nos espaços. Abordando esse fenômeno, Figueiredo \& Schraiber (2011) problematizaram a materialidade do corpo enquanto incorporação das práticas de gênero ou, ainda, de uma encarnação social de gênero, afirmando a impossibilidade de ignorarmos os significados que o corpo adquire na interpretação social do gênero e as construçóes sobre ele para estabelecer as representaçóes e as formas de vivê-lo e praticá-lo no cotidiano.

Essas são consideraçôes que se somam a conclusôes de estudos realizados em outras áreas. Em seu trabalho na Enfermagem, Pereira (2008) argumentou que o discurso baseado em uma suposta natureza feminina, e que coloca as mulheres na posição de cuidadoras para atuação como enfermeiras, é o mesmo discurso baseado em uma suposta natureza masculina e que resulta na colocação profissional de homens em áreas específicas da Enfermagem. Como se vê, parte da construção das categorias masculino e feminino ocorre através de "[...] prescriçôes e julgamentos que responsabilizam e conformam 
habilidades e preferências, com forte expressäo no âmbito da divisão das responsabilidades e do trabalho", conforme afirmou Biroli (2016, p. 720).

Apesar de terem sido ansiados em seus ambientes de trabalho, alguns participantes notam que, nos primeiros contatos interprofissionais, é comum que colegas de outras profissóes expressem expectativas de que um profissional homem exerça funçôes diferentes das que são mais comumente atribuídas ao terapeuta ocupacional naquele contexto, como relata Lucas: "Quando eu chego é comum me perguntarem se eu sou médico [...]". Ele também destaca episódios vividos em um Centro de Reabilitação, em que supunham que ele fosse um fisioterapeuta - "Porque acho que tinha uma expectativa de que, se eu era homem, tinha que ser fisioterapeuta naquele espaço". Os fatos narrados parecem refletir o que nos lembra Pereira (2008) ao afirmar que no imaginário social estấo associados ao universo masculino os trabalhos que remetem ao político e à produção, enquanto ao feminino se atribuem funçôes ligadas à esfera doméstica e a posiçôes subalternas ao homem, acentuando a dicotomia existente no mundo do trabalho e as delimitaçóes estereotipadas em torno de atividades profissionais femininas e masculinas. Cabe, assim, interrogar como tem sido interpretado socialmente o homem que atua em profissóes construídas como femininas, como a terapia ocupacional. Em relação ao seu status profissional, pode estar em uma posição privilegiada em relação às mulheres e inferiorizado em relação a outros homens? Estariam sendo vistos como sujeitos com relaçōes conflituosas com as normas de gênero instituídas?

Esses fatos convergem, ademais, com a realidade que Beagan \& Fredericks (2018) encontraram no tocante às atitudes de reforço à heteromasculinidade dirigidas aos terapeutas ocupacionais homens no Canadá. Em seus estudos, os autores trabalharam com dados que atestaram que homens terapeutas ocupacionais estão mais presentes que as mulheres em cargos de gerência e no trabalho empreendedor, e que os estereótipos atravessam os contextos profissionais desencadeando divisōes internas de gênero na profissão. Como exemplo, mostram que homens são levados a cargos de gerência (mais bem remunerados e supostamente de maior prestígio profissional), por vezes até mesmo involuntariamente. São promoçóes que predominam em práticas que envolvem a atenção a crianças ou os cuidados que requerem extenso contato físico com os pacientes, como aqueles ligados à higiene, transferências e alimentaçăo, afastando intencionalmente os homens de tais funçôes. Isso se daria, para Beagan \& Fredericks (2018), em razão da presença de estereótipos - neste caso ligados a uma suposta falta de controle dos homens sobre a sua sexualidade - que geram desconforto entre as pessoas que recebem os serviços e, consequentemente, influenciam na configuração de relaçóes de gênero na terapia ocupacional. Além disso, as autoras identificaram processos informais de manutenção e reforço da heteromasculinidade por meio da segregaçăo de gênero na profissão, constatando em discussōes nas mídias sociais o incentivo à inserção de homens em áreas como a de terapia de mão, e menos em áreas que exigem maior contato corporal, como, por exemplo, aquelas diretamente relacionadas às atividades de vida diária. As autoras, contudo, concluem que homens podem enfrentar desconfortos em uma profissão composta predominantemente por mulheres, mas que, no caso da terapia ocupacional, estes não são convertidos em barreiras estruturais. E que os homens, por fim, acabam sendo beneficiados pelas promoçôes profissionais.

Envolvendo os limites colocados por questóes de gênero, quatro dos cinco entrevistados afirmaram que percebem que ser homem tem influência restritiva no primeiro acolhimento de mulheres vítimas de violência. Lucas coloca: "[...] quando chega nessa dimensäo da vida, eu tenho uma dificuldade, preciso de um pouco mais de tato e as coisas às vezes não se aprofundam. 
Eu não tenho a mesma entrada que talvez uma colega mulher consiga". Outro entrevistado, Caio, menciona suas experiências ao reconhecer essas situaçóes:

Acho que é a gente poder olhar [...] de uma forma mais cuidadosa e [...] compartilhar. Poder dizer [...]: olha eu acho que aqui fica um pouco dificil; tudo bem para você continuar? Se a pessoa falava que não, [eu dizia]: tá ok, então a gente para por aqui. Eu chamava uma outra colega para [...] continuar, num outro dia.

Em outras circunstâncias, são as mulheres que colocam esse limite, recusando-se a receber atendimento de profissionais homens, como relata Mateus: "Já aconteceu isso comigo, assim: olha, tem questóes da minha história de vida..., acontecimentos da minha vida com o sexo masculino que náo dá [para tratar com você]”"

Nessas narrativas, encontramos o corpo intrinsecamente relacionado ao desconforto dos homens no acolhimento a mulheres vítimas de violência, dialogando com as dificuldades referidas por Schraiber \& D’Oliveira (2008). As autoras mostraram que, por se perceberem como autores da violência, ainda que na dimensão simbólica, os profissionais homens podem ocupar lugares sociais embaraçosos, comprometendo a prática assistencial nessas condiçóes.

\section{Consideraçóes Finais}

Questóes relacionadas ao gênero atravessam diferentes interaçóes entre terapeutas ocupacionais, entre estes e outros trabalhadores, e também suas relaçóes com os usuários dos serviços. Essas questóes, que acompanharam e deixaram marcas importantes nas experiências dos terapeutas ocupacionais com quem dialogamos em nosso estudo, são percebidas como parte das desigualdades que integram as relaçóes sociais entre gêneros na sociedade de modo geral e, em grande medida, são transpostas enquanto privilégios masculinos para espaços profissionais da categoria. $\mathrm{Na}$ percepção desses terapeutas ocupacionais - que atuam em unidades assistenciais da área da saúde e na maior metrópole do país -, as desigualdades entre gênero estão ligadas a situaçóes de injustiça e à dominação masculina no mundo do trabalho, o que sugere haver entre eles um alto nível de consciência das implicaçóes de gênero nas relaçóes interprofissionais. $\mathrm{O}$ mesmo não acontece com a mesma clareza, contudo, quando o foco se coloca nas relaçóes com usuários.

Diante dos resultados e discussóes permitidas pelo estudo, cabe considerar que outros aspectos podem estar presentes na composição de um quadro mais complexo sobre as questôes de gênero na terapia ocupacional no Brasil. O estudo realizado se deteve sobre experiências e percepçóes de homens terapeutas ocupacionais, não abrangendo o que parece ser também uma tarefa urgente: ouvir as mulheres sobre questóes de gênero no trabalho.

Além disso, sabemos que o princípio hierárquico da divisão sexual do trabalho instala desigualdades salariais importantes entre profissionais homens e mulheres que desempenham as mesmas funçôes (Hirata \& Kergoat, 2007). Mais recentemente, Silva (2020) observou que, apesar das profissóes das ciências biológicas, da saúde e afins serem exercidas predominantemente por mulheres, essas recebem, em média, remuneração equivalente a $60 \%$ do salário dos profissionais homens da mesma área. Enquanto no Canadá a diferença salarial entre os profissionais da terapia ocupacional vem sendo identificada 
regularmente - sendo a média salarial das terapeutas ocupacionais mulheres $79,5 \%$ dos salários recebidos em média pelos homens em 2015, segundo Beagan \& Fredericks (2018) -, no Brasil ainda não contamos com esses dados para integrá-los à discussão.

Por fim, vale afirmar que, embora a incursão nos estudos feministas ao longo do desenvolvimento da pesquisa tenha sido apenas introdutória, essa foi a condição essencial para que pudéssemos adotar uma perspectiva a partir da qual a presença dos homens na profissão fosse compreendida no âmbito das relaçóes efetivamente vividas entre os gêneros no universo profissional.

\section{Referências}

Aktinson, R., \& Flint, J. (2001). Accessing hidden and hard-to-reach populations: snowball research strategies. Social Research Update, 33(1), 1-4.

Arilha, M., Ridenti, S. G. U., \& Medrado, B. (1998). Homens e masculinidades: outras palavras. São Paulo: Ecos Editora 34.

Beagan, B. L., \& Fredericks, E. (2018). What about the men? Gender parity in occupational therapy. Canadian Journal of Occupational Therapy, 85(2), 137-145. PMid:29490480. http://dx.doi.org/10.1177/0008417417728524.

Bento, B. (2015). Homem não tece a dor: queixas e perplexidades masculinas. Natal: UFRN.

Birioukova, A., So, K., \& Barker, D. (2012). The male occupational therapist: demographics, issues and recommendations. Occupational Therapy Now, 14(1), 18-20.

Biroli, F. (2016). Divisão sexual do trabalho e democracia. Dados - Revista de Ciências Sociais, 59(3), 719754. http://dx.doi.org/10.1590/00115258201690.

Butler, J., \& Lourties, M. (1998). Actos performativos y constitución del género: un ensayo sobre fenomenología y teoría feminista. Debate Feminista, 18, 296-314. http://dx.doi.org/10.22201/cieg.2594066xe.1998.18.526.

Connell, R. W. (1995). Políticas de masculinidade. Educação e Realidade, 20(2), 241-282.

Connell, R. W., \& Messerschmidt, J. W. (2013). Masculinidade hegemônica: repensando o conceito. Revista Estudos Feministas, 21(1), 241-282. http://dx.doi.org/10.1590/S0104-026X2013000100014.

Conselho Regional de Fisioterapia e Terapia Ocupacional - CREFITO 3. (2021). Pesquisa de inscritos. Recuperado em 17 de fevereiro de 2021, de http://www.crefito3.org.br/dsn/app_site/est_prof.asp

Duarte, R. (2004). Entrevistas em pesquisas qualitativas. Educar em Revista, (24), 213-225. http://dx.doi.org/10.1590/0104-4060.357.

Figueiredo, M. O., Zambulim, M. C., Emmel, M. L. G., Fornereto, A. P. N., Lourenço, G. F., Joaquim, R. H. V. T., \& Barba, P. D. (2018). Terapia ocupacional: uma profissão relacionada ao feminino. História, Ciência \& Saúde - Manguinhos, 25(1), 115-126. PMid:29694522. http://dx.doi.org/10.1590/S0104-59702018000100007.

Figueiredo, W. S., \& Schraiber, L. B. (2011). Concepções de gênero de homens usuários e profissionais de saúde de serviços de atenção primária e os possíveis impactos na saúde da populaçáo masculina. Ciência \& Saúde Coletiva, 16(Supl. 1), 935-944. http://dx.doi.org/10.1590/S141381232011000700025.

Gardiner, J. K. (2002). Masculinity studies and feminist theory. Columbia: Columbia University Press.

Grollmus, N. S. (2012). La construcción social de la masculinidad: poder, hegemonía y violencia. Psicología, Conocimiento y Sociedad, 2(2), 7-65.

Hirata, H., \& Kergoat, D. (2007). Novas configurações da divisão sexual do trabalho. Cadernos de Pesquisa, 37(132), 595-609. http://dx.doi.org/10.1590/S0100-15742007000300005.

Lopes, R. E. (1999). Cidadania, políticas públicas e terapia ocupacional no contexto das açóes de saúde mental e saúde da pessoa portadora de deficiência no município de São Paulo (Tese de doutorado).

Universidade Estadual de Campinas, Campinas. 
Matos, I. B., Toassi, R. F. C., \& Oliveira, M. C. (2013). Profissóes e ocupaçóes de saúde e o processo de feminização: tendências e implicaçóes. Athenea Digital, 13(2), 239-244. http://dx.doi.org/10.5565/rev/athenead/v13n2.1119.

Matos, M. (2008). Teorias de gênero ou teorias e gênero? Se e como os estudos de gênero e feministas se transformaram em um campo novo para as ciências. Estudos Feministas, 16(2), 333-357. http://dx.doi.org/10.1590/S0104-026X2008000200003.

Maxim, A. J. M., \& Rice, M. S. (2018). Men in occupational therapy: issues, factors, and perceptions. The American Journal of Occupational Therapy, 72(1), 1-8. PMid:29280725. http://dx.doi.org/10.5014/ajot.2018.025593.

Minayo, M. C. D. S., Deslandes, S. F., \& Gomes, R. (2016). Pesquisa social: teoria, método e criatividade. Petropólis: Vozes.

Monzeli, G. A., Morrison, R., \& Lopes, R. E. (2019). Histórias da terapia ocupacional na América Latina: a primeira década de criação dos programas de formação profissional. Cadernos Brasileiros de Terapia Ocupacional, 27(2), 235-250. http://dx.doi.org/10.4322/2526-8910.ctoao1631.

Nolasco, S. (1993). O mito da Masculinidade. Rio de Janeiro: Rocco.

Oliveira, P. P. (1998). Discursos sobre a masculinidade. Estudos Feministas, 6(1), 91-112.

Oliveira, P. P. (2004). A construção social da masculinidade. Belo Horizonte: UFMG/IUPERJ.

Pereira, P. F. (2008). Homens na enfermagem: atravessamentos de gênero na escolha, formação e exercício profissional (Dissertação de mestrado). Universidade Federal do Rio Grande do Sul, Porto Alegre.

Pinto, C. R. J. (2010). Feminismo, historia e poder. Revista de Sociologia e Politica, 18(36), 15-23. http://dx.doi.org/10.1590/S0104-44782010000200003.

Rago, M. (1996). Adeus ao feminismo? Feminismo e (pós)modernidade no Brasil. Cadernos AEL, 2(3-4), $11-43$.

Schraiber, L. B., \& D’Oliveira, A. F. P. L. (2008). Violência contra as mulheres e promoção dos direitos humanos: a contribuição do campo da saúde. Divulgação em Saúde para Debate, (41), 47-55.

Scott, J. (1995). Gênero: uma categoria útil de análise histórica. Educação e Realidade, 20(2), 71-99.

Silva, L. P. (2020). Mercado de trabalho e as diferenças de gênero: o caso das ocupaçôes de nivel superior no Brasil (2004-2013) (Tese de doutorado). Universidade Estadual de Campinas, Campinas.

Silva, S. G. (2006). A crise da Masculinidade: uma crítica à identidade de gênero e à literatura masculinista. Psicologia, Ciência e Profissão, 26(1), 118-131. http://dx.doi.org/10.1590/S141498932006000100011.

Vogel, B., Benneton, J., \& Goubert, J. P. (2002). Terapia ocupacional: história de uma profissão feminina. Revista do Centro de Estudos de Terapia Ocupacional, 7(7), 47.

http://dx.doi.org/10.1590/S0104-59702018000100007.

\section{Contribuiçáo dos Autores}

Gabriel Paiva Ferreira: desenho do estudo, organização de fontes, coleta e análise de dados, redação do texto e revisão final. Marta Carvalho de Almeida: orientação do estudo, apoio na análise dos dados e na redaçáo do texto e revisão final. Todos os autores aprovaram a versão final do texto.

Autor para correspondência

Marta Carvalho de Almeida

e-mail: mcarmei@usp.br

\section{Editora de seçáo}

Profa. Dra. Adriana Miranda Pimentel 